\title{
A phenetic study of the genus Rasahus Amyot \& Serville (Heteroptera, Reduviidae)
}

\author{
María del Carmen Coscarón
}

Coscarón, M. C. 1990: A phenetic study of the genus Rasahus Amyot \& Serville (Heteroptera, Reduviidae). — Entomol. Fennica 1:131-144.

Cluster analysis by four methods and a principal component analysis were performed using data on 24 morphological characters of 27 species of the genus Rasahus (Peiratinae). The results obtained by the different techniques show general agreement. They confirm the present number of taxa and reveal the existence within the genus of three groups of species: scutellaris, hamatus and vittatus. The scutellaris group is constituted by R. aeneus (Walker), R. maculipennis (Lepelletier and Serville), $R$. bifurcatus Champion, $R$. castaneus Coscarón, $R$. guttatipennis (Stål), $R$. flavovittatus Stål, $R$. costarricensis Coscarón, R. scutellaris (Fabricius), R. atratus Coscarón, R. peruensis Coscarón, $R$. paraguayensis Coscarón, $R$. surinamensis Coscarón, $R$. albomaculatus Mayr, $R$. brasiliensis Coscarón and $R$. sulcicollis (Serville). The hamatus group contains $R$. rufiventris (Walker), $R$. hamatus (Fabricius), $R$. amapaensis Coscarón, $R$. arcitenens Stål, $R$. limai Pinto, $R$. angulatus Coscarón, $R$. thoracicus Stål, $R$. biguttatus (Say), $R$. arcuiger (Stål), $R$. argentinensis Coscarón and $R$. grandis Fallou. The vittatus group contains $R$. vittatus Coscarón. The characters used to separate the groups of species are: shape of the pygophore, shape of the parameres, basal plate complexity, shape of the postocular region and hemelytra pattern. Illustrations of the structures of major diagnostic importance are included.

María del Carmen Coscarón, División Entomología, Facultad de Ciencias Naturales y Museo de La Plata, Paseo del Bosque S/N, 1900 La Plata, Argentina (Temporary address: Zoological Museum, University of Helsinki, P. Rautatiekatu 13, SF-00100 Helsinki, Finland)

\section{Introduction}

At present, the genus Rasahus consists of 27 species with Nearctic and Neotropical distribution.

The systematics of this genus has recently been revised (Coscarón 1983), but the phenetic relationships of its species are still very unclear. The present study was undertaken because it was thought that numerical techniques could profitably be applied to quantify the taxonomic distance between the species of the genus and to determine the relation between the characters and their discriminatory values. 


\section{Material and methods}

The numerical techniques used follow Crisci \& López-Armengol (1983).

\subsection{Selection of the Operational Taxonomical Units (OTU's)}

In this study the 27 species of Rasahus constitute the operational taxonomic units (OTU's). They are: R.aeneus (Walker) (OTU 1), R. maculipennis (Lepelletier and Serville) (OTU 2), R. rufiventris (Walker) (OTU 3), R. bifurcatus Champion (OTU 4), R. flavovittatus (Stål) (OTU 5), R. guttatipennis (Stål) (OTU 6), R. atratus Coscarón (OTU 7), $R$. arcitenens Stäl (OTU 8), R. arcuiger (Stål) (OTU 9), R argentinensis Coscarón (OTU 10), $R$. grandis Fallou (OTU 11), R. limai Pinto (OTU 12), R. thoracicus Stål (OTU 13), R. vittatus Coscarón (OTU 14), $R$. amapaensis Coscarón (OTU 15), R. hamatus (Fabricius) (OTU 16), $R$. biguttatus (Say) (OTU 17), R. surinamensis Coscarón (OTU 18), R. albomaculatus (Mayr) (OTU 19), R. peruensis Coscarón (OTU 20), R. paraguayensis Coscarón (OTU 21), R. brasiliensis Coscarón (OTU 22), R. sulcicollis (Serville) (OTU 23), R. scutellaris (Fabricius) (OTU 24), R. castaneus Coscarón (OTU 25), R. angulatus Coscarón (OTU 26) and $R$. costarricensis Coscarón (OTU 27).

The material examined belongs to the following institutions: The American Museum of Natural History (U.S.A.), British Museum (Natural History) (England), California Academy of Sciences (U.S.A.), Canadian National Collections of Insects, Arachnids and Nematodes (Canada), Fundación Miguel Lillo (Argentina), Instituto Entomológico San Miguel (Argentina), Museo Argentino de Ciencias Naturales (Argentina), Museo de Ciencias Naturales La Plata (Argentina), Museo Emilio Goeldi (Brasil), Muséum National d'Histoire Naturelle (France), Museu de Zoología de Sâo Paulo (Brazil), Naturhistoriska Riksmuseet (Sweden), Rijksmuseum van Natuurlijke Historie en Geologie (The Netherlands), Snow Entomological Museum, University of Kansas (U.S.A.), United States National Museum (U.S.A.), Universitetets Zoologiske Museum (Denmark), Zoologisches Museum, der
Humboldt Universität zu Berlin (D.D.R.), Mr. Martinez (personal collection).

\subsection{Selection of the characters}

The character set is composed of features of the external morphology of the body and the male genitalia.

The terminology used for the external morphology is according to Lent \& Jurberg (1966) and Lent \& Wygodzinsky (1979). The terminology employed for the characters of the male genitalia is that proposed by Dupuis $(1955,1963)$ and Davis $(1966,1969)$. The methodology for extraction, dissection, inflation and drawings of the male genitalia has been explained elsewhere (Coscarón 1983). Figs. 1-24 and 29-49 depict the characters used in the study.

Characters of the female genitalia are not used in this paper because there is a significant number of species for which the females are still unknown.

The characters of the external morphology number 18 and those of the male genitalia 6 .

The set includes quantitative continuous characters (3), ratios (7) and qualitative characters (14). For each species (OTU), 5 males were measured (when possible) and the mean value was used. Indications of how the measurements were made are given in Figs. 1-19.

The coding was based on the kind of data. For quantitative data and ratios the value is given; qualitative data are coded as absent (0) or present (1), or, if multistate, as $1,1.5$ or 2.

The characters, character states and coding are listed below.

\section{A. Characters from external morphology}

1 Total length (Fig. 1)

2 Width of pronotum (Fig. 1)

3 Width of abdomen (Fig. 1)

4 Width of head/length of head (at eye height) (Fig. 1)

5 Length pronotum/length head (Fig. 1)

6 Length postocular region/length anteocular region (Fig. 1)

7 Length rostral segment II/length rostral segment I (Fig. 2) 
8 Length rostral segment III/length rostral segment I (Fig. 2)

9 Height of head/eyes height (Fig. 2)

10 Body shape

(1) stout (Fig. 37)

(2) slender (Fig. 34)

11 Postocular region

(1) angular (Fig. 3)

(2) rounded (Fig. 4)

12 Eye position

(1) not surpassing nor under nor upper surface of head (Fig. 2)

(2) surpassing under or upper surface of head or under and upper surface of head (Fig. 6)

13 Scutellum

(1) not acuminate or very slightly acuminate (Fig. 7)

(1.5) acuminate

(2) very acuminate (Fig. 9)

14 Hind femur coloration

(1) uniform (Fig. 34)

(2) more than one colour (Fig. 29)

15 Hemelytra with a well defined oval dot over $\mathrm{Cu}$

(0) absence (Fig. 44)

(1) presence (Fig. 42)

16 Conexivum

(1) visible dorsally (Fig. 29)

(2) not visible dorsally (Fig. 37)

17 Conexivum

(1) homogeneous (Fig. 10)

(2) not homogeneous (Fig. 11)

18 Eighth sternite pilosity

(0) absent (Fig. 12)

(1) present (Fig. 13)

\section{B. Characters from the male genitalia}

19 Shape of pygophore

(1) rounded (Fig. 14)

(1.5) subrectangular (Fig. 15)

(2) quadrangular (Fig. 16)

20 Inferior edge of pygophore

(1) straight (Fig. 17)

(1.5) sinuose (Fig. 18)

(2) with an evagination (Fig. 19)

21 Median distal region of medial process of pygophore

(1) not curved (Figs. 17, 20)

(2) curved (Figs. 18, 19)
22 Medial process of pygophore: length/width (Fig. 19)

23 Parameres

(1) subrectangular (Fig. 21)

(2) subtriangular (Fig. 22)

24 Basal plate

(1) simple (Fig. 23)

(2) complex (Fig. 24)

Once the data for each of the taxa had been recorded, a basic data matrix was constructed for 27 OTU's for 24 characters (Table 1).

\subsection{Data processing}

The data were analysed by five methods, using four cluster analyses and one ordination, as shown in the flow chart (Fig. 25). The computational work was done at the Centro de Estudios Superiores para el Procesamiento de la Información (CESPI) of the University of La Plata, using NTSYS programs.

The BDM was standardized (BDMS) by the characters, to remove the unequal weights imposed on it by the use of different scales of measurement. Details of the method and computational procedures may be found in Sneath \& Sokal (1973)

\section{Cluster analysis}

The cophenetic correlation coefficient ( $r$ ) (CCC) was computed here as a measure of distortion for each of the methods used.

Method 1. The "Taxonomic Distance Coefficient" (Sneath \& Sokal 1973) pair between the OTU's and the unweighted Pair-Group Method using arithmetic averages (UPGMA) for the construction of the phenogram of distances were employed; CCC was also computed.

Method 2. A OTU $\times$ OTU distance matrix was obtained from the BDMS by calculating the "Manhattan distance" between pairs of OTU's. The distance matrix served as input in the calculation of a "Prim Network".

Method 3. The same procedure as Method 1 was used, except that the similarity coefficient employed here was the Pearson product-moment correlation coefficient. 


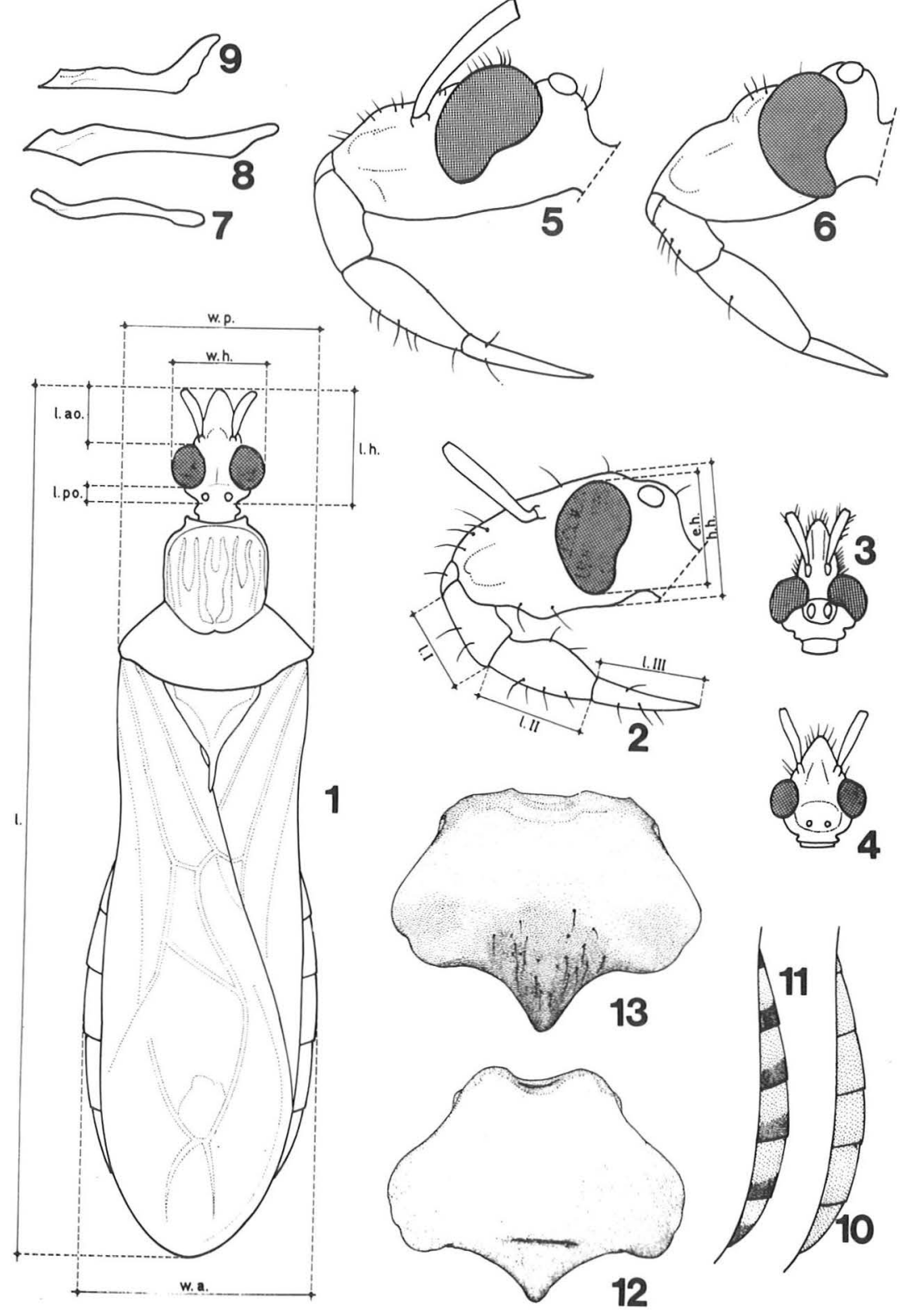

Figs. $1-13$. Characters of the external morphology. -1 . Head, pronotum and abdomen, dorsal view $(I=$ length; w.p. $=$ width of pronotum; w.a. $=$ width of abdomen; I.h. $=$ length of head; $w . h .=$ width of head; I.p. $=$ length of pronotum; I.ao. = length of anteocular region; I.po. = length of postocular region). -2 . Head, lateral view (I.I. = length of rostral segment I; I.II. = length of rostral segment II; I.III. = length of rostral segment III; h.h. = height of head; e.h. = eye height). -3 and 4 . Head shape, dorsal view: 3 , angular; 4 , rounded. $-2,5$ and 6 . Eyes position surpassing: 2 , nor under nor upper surface of head; 5 , upper surface of head; 6 , under and upper surface of head. $-7,8$ and 9 . Scutellum shape; 7 , not acuminate; 8 , accuminate and 9 , very accuminate. -10 and 11 . Conexivum pattern: 10, homogeneous; 11 , not homogeneous. - 12 and 13. Eighth sternite: 12, without pilosity; 13, with pilosity. 

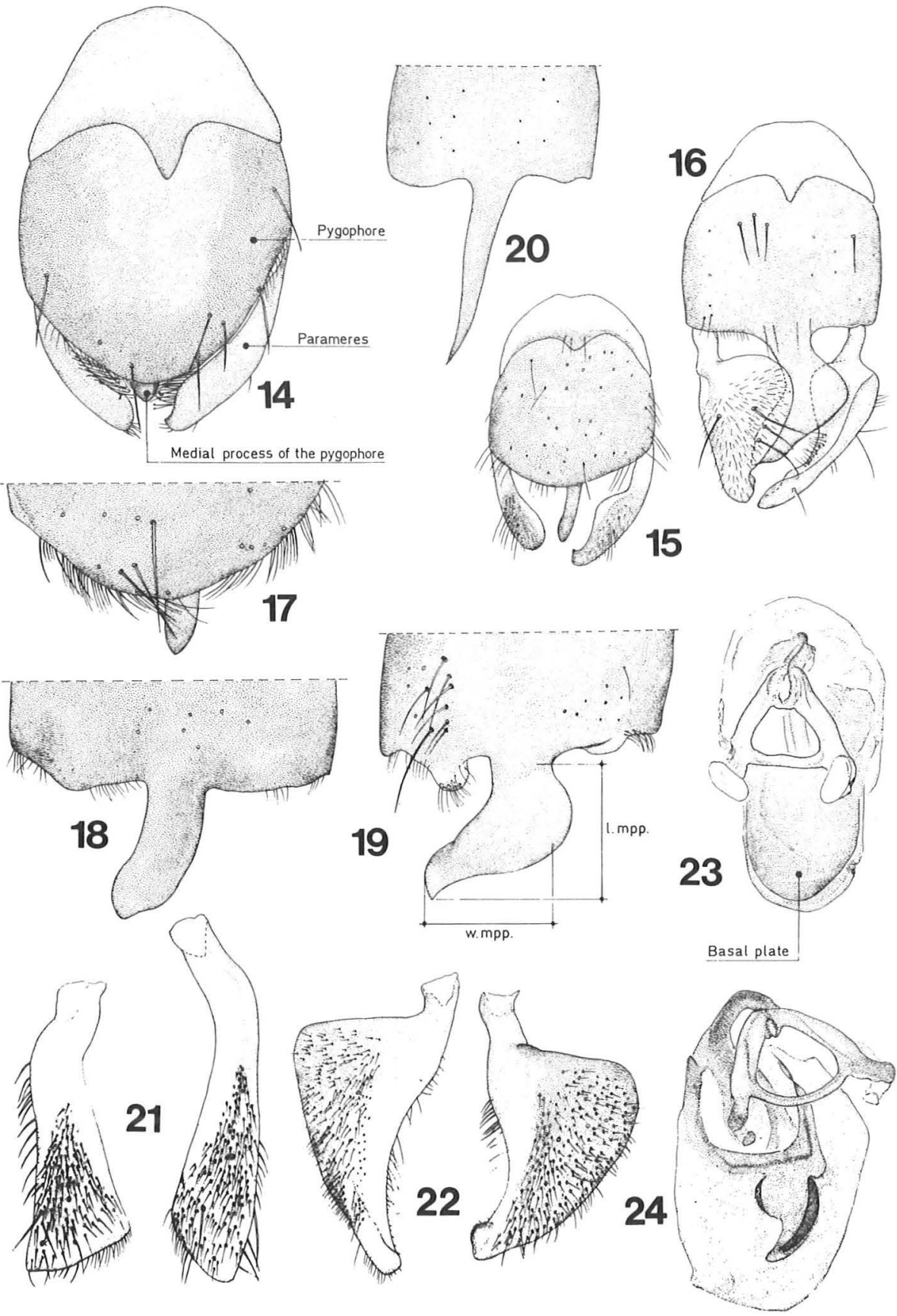

Figs. 14-24. Characters of the male genitalia. $-14,15$ and 16. Pygophore shape: 14, rounded; 15, subquadrangular; 16 , subrectangular. $-17,18$ and 19. Inferior edge of pygophore: 17 , straight; 18 , sinuose; 19 , with an evagination. $-17,18,19$ and 20. Median distal region of medial process of the pygophore: 17 and 20 , not curved; 18 and 19, curved. -19 . Dimensions of medial process of pygophore: I.m.p.p. = length; w.m.p.p. $=$ width. -21 and 22. Paramere shapes: 21 , subrectangular; 22, subtriangular. -23 and 24 . Basal plate complexity: 23, simple; 24 , complex. 
Table 1. Basic data matrix for 27 OTU (species) scored for 24 characters ( $-=$ not comparable).

\begin{tabular}{|c|c|c|c|c|c|c|c|c|c|}
\hline Character: & 1 & 2 & 3 & 4 & 5 & 6 & 7 & 8 & 9 \\
\hline R. aeneus & 9.10 & 2.50 & 2.80 & 0.9 & 2.7 & 0.5 & 1.95 & 1.30 & 0.81 \\
\hline R. maculipennis & 13.85 & 3.30 & 3.60 & 1 & 1.8 & 0.6 & 1.15 & 1.19 & 0.86 \\
\hline R. rufiventris & 13.60 & 3.00 & 3.30 & 0.7 & 1.5 & 0.4 & 1.76 & 1.16 & 1.02 \\
\hline R. bifurcatus & 13.30 & 3.10 & 4.00 & 0.7 & 1.6 & 0.4 & 1.46 & 1.12 & 0.71 \\
\hline R. flavovitatus & 14.60 & 3.50 & 4.00 & 1.0 & 2.2 & 0.6 & 1.68 & 1.32 & 0.72 \\
\hline R. guttatipennis & 13.05 & 3.30 & 3.95 & 0.8 & 1.6 & 0.5 & 1.82 & 1.39 & 0.68 \\
\hline R. atratus & 16.55 & 4.05 & 4.65 & 0.8 & 1.6 & 0.5 & 1.42 & 1.02 & 0.83 \\
\hline R. arcitenens & 14.35 & 3.30 & 4.00 & 1.0 & 2.0 & 0.2 & 2.00 & 1.60 & 1.00 \\
\hline R. arcuiger & 13.80 & 3.45 & 3.80 & 0.7 & 2.4 & 0.2 & 0.95 & 0.70 & 0.70 \\
\hline R. argentinensis & 18.00 & 4.10 & 4.10 & 0.8 & 1.8 & 0.3 & 1.22 & 0.85 & 0.85 \\
\hline R. grandis & 21.15 & 5.00 & 5.50 & 0.8 & 1.5 & 0.2 & 1.66 & 1.90 & 1.27 \\
\hline R. limai & 23.65 & 5.30 & 5.45 & 1.0 & 2.1 & 0.4 & 2.20 & 1.40 & 0.90 \\
\hline R. thoracicus & 18.80 & 4.35 & 5.15 & 0.3 & 1.8 & 0.3 & 1.48 & 1.20 & 0.69 \\
\hline R. vittatus & 13.80 & 3.30 & 3.60 & 0.7 & 1.5 & 0.3 & 1.30 & 1.30 & 0.94 \\
\hline R. amapaensis & 15.30 & 3.30 & 0.60 & 0.6 & 1.6 & 0.5 & 1.55 & 1.17 & 1.05 \\
\hline R. hamatus & 15.45 & 4.05 & 4.60 & 0.7 & 1.3 & 0.4 & 1.85 & 1.32 & 1.06 \\
\hline R. biguttatus & 20.15 & 5.00 & 5.50 & 0.3 & 1.9 & 0.5 & 1.80 & 1.06 & 0.78 \\
\hline R. surinamensis & 16.55 & 5.85 & 6.60 & 0.8 & 1.8 & 0.6 & 1.31 & 0.85 & 0.75 \\
\hline R. albomaculatus & 23.20 & 5.70 & 5.80 & 0.6 & 1.5 & 0.3 & 1.86 & 1.00 & 0.79 \\
\hline R. peruensis & 16.60 & 4.10 & 4.50 & 0.7 & 1.1 & 0.4 & 1.82 & 1.39 & 0.70 \\
\hline R. paraguayensis & 16.00 & 3.80 & 4.60 & 0.7 & 1.6 & 0.3 & 1.43 & 1.36 & 0.70 \\
\hline R. brasiliensis & 21.65 & 5.30 & 5.60 & 0.7 & 1.3 & 0.4 & 1.46 & 1.10 & 0.95 \\
\hline R. sulcicollis & 16.85 & 4.30 & 4.65 & 0.6 & 1.5 & 0.3 & 1.21 & 0.86 & 0.87 \\
\hline R. scutellaris & 10.30 & 2.80 & 3.00 & 0.8 & 1.5 & 0.4 & 0.89 & 0.89 & 0.71 \\
\hline R. castaneus & 13.10 & 3.30 & 3.60 & 0.6 & 1.7 & 0.4 & 1.83 & 0.91 & 0.86 \\
\hline R. angulatus & 22.10 & 5.05 & 5.50 & 0.8 & 1.8 & 0.6 & 1.66 & 1.12 & 0.93 \\
\hline R. costarricensis & 11.90 & 2.95 & 3.80 & 1.0 & 2.0 & 0.6 & 1.60 & 0.95 & 0.75 \\
\hline
\end{tabular}

Character:

$\begin{array}{lllllllllllllll}10 & 11 & 12 & 13 & 14 & 15 & 16 & 17 & 18 & 19 & 20 & 21 & 22 & 23 & 24\end{array}$

R. aeneus

R. maculipennis

R. rufiventris

R. bifurcatus

R. flavovitatus

R. guttatipennis

R. atratus

R. arcitenens

$R$. arcuiger

$R$. argentinensis

$R$. grandis

R. limai

R. thoracicus

$R$. vittatus

R. amapaensis

$R$. hamatus

$R$. biguttatus

$R$. surinamensis

R. albomaculatus

R. peruensis

$R$. paraguayensis

$R$. brasiliensis

R. sulcicollis

R. scutellaris

R. castaneus

$R$. angulatus

R. costarricensis

\begin{tabular}{rrrrrrrrrrrrrrr}
\hline 2 & 2 & 1 & 1 & 2 & 0 & 1 & 2 & - & - & - & - & - & - & - \\
2 & 2 & 1 & 1 & 2 & 0 & 1 & 2 & 0 & 2 & 1.5 & 1 & 4.58 & 2 & 1 \\
2 & 2 & 2 & 1 & 2 & 1 & 2 & 2 & 0 & 1 & 1 & 1 & 1.36 & 1 & 1 \\
2 & 2 & 1 & 1.5 & 2 & 0 & 1 & 2 & 0 & 2 & 2 & 2 & 2.00 & 2 & 1 \\
2 & 2 & 2 & 1.5 & 2 & 0 & 1 & 2 & 0 & 2 & 2 & 2 & 2.75 & 2 & 1 \\
2 & 2 & 1 & 1 & 2 & 0 & 1 & 2 & 1 & 2 & 1.5 & 2 & 2.47 & 2 & 1 \\
2 & 2 & 1 & 1.5 & 1 & 0 & 1 & 1 & 1 & 2 & 1.5 & 2 & 2.00 & 2 & 1 \\
2 & 2 & 2 & 1.5 & 1 & 1 & 1 & 2 & 1 & 1 & 1 & 1 & 1.14 & 1 & 1 \\
2 & 2 & 1 & 1.5 & 2 & 1 & 1 & 2 & 1 & 1 & 1 & 1 & 1.45 & 1 & 1 \\
1 & 1 & 1 & 1.5 & 1 & 1 & 2 & 1 & 0 & 1 & 1 & 1 & 1.29 & 1 & 1 \\
1 & 1 & 2 & 1 & 1 & 1 & 2 & 1 & 1 & 1 & 1 & 1 & 1.09 & 1 & 1 \\
1 & 1 & 2 & 1.5 & 1 & 1 & 1 & 2 & 0 & 1 & 1 & 1 & 1.07 & 1 & 1 \\
1 & 1 & 2 & 1.5 & 1 & 1 & 1 & 2 & 1 & 1 & 1 & 1 & 1.16 & 1 & 1 \\
2 & 2 & 2 & 2 & 2 & 0 & 1 & 2 & 1 & 1.5 & 1 & 1 & 3.88 & 2 & 2 \\
2 & 1 & 2 & 1 & 2 & 1 & 1 & 1 & 0 & 1 & 1 & 1 & 1.70 & 1 & 1 \\
1 & 2 & 2 & 1 & 2 & 1 & 1 & 2 & 0 & 1 & 1 & 1 & 1.20 & 1 & 1 \\
1 & 1 & 1 & 1.5 & 2 & 1 & 1 & 2 & 0 & 1 & 1 & 1 & 1.36 & 1 & 1 \\
2 & 2 & 1 & 1.5 & 2 & 0 & 1 & 2 & 1 & 2 & 2 & 2 & 1.24 & 1 & 1 \\
1 & 2 & 1 & 1.5 & 2 & 0 & 1 & 2 & 1 & 2 & 2 & 2 & 1.85 & 2 & 1 \\
2 & 2 & 2 & 1.5 & 1 & 0 & 1 & 1 & 1 & 2 & 1.5 & 2 & 1.71 & 2 & 1 \\
2 & 2 & 1 & 2 & 1 & 0 & 1 & 2 & 1 & 2 & 2 & 2 & 1.83 & 2 & 1 \\
1 & 2 & 2 & 1 & 2 & 0 & 1 & 1 & 1 & 2 & 1.5 & 2 & 2.05 & 2 & 1 \\
1 & 2 & 1 & 1 & 2 & 1 & 1 & 2 & 1 & 2 & 1.5 & 2 & 2.00 & 2 & 1 \\
2 & 2 & 1 & 1 & 2 & 0 & 1 & 2 & 1 & 2 & 1.5 & 2 & 1.68 & 2 & 1 \\
2 & 2 & 1 & 1 & 2 & 0 & 1 & 2 & 0 & 2 & 1.5 & 2 & 2.33 & 2 & 1 \\
1 & 1 & 2 & 1 & 2 & 1 & 1 & 2 & 1 & 1 & 1 & 1 & 1.00 & 1 & 1 \\
2 & 2 & 1 & 1.5 & 2 & 0 & 1 & 2 & 0 & 2 & 1.5 & 2 & 1.77 & 2 & 1 \\
\hline
\end{tabular}




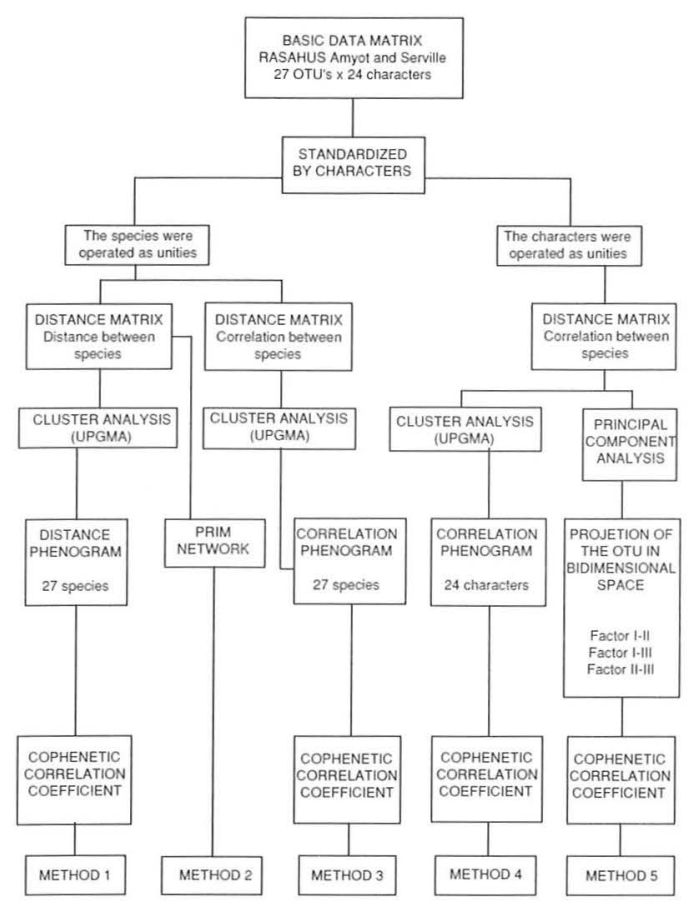

Fig. 25. Flow chart of the data processing.

Method 4. The same steps and coefficients were used as for Method 1, the only difference being that the characters were treated as taxonomic units and the OTU as characters (R Technique). The graph obtained was a phenogram of the distances between characters.

\section{Ordination}

The common ordination technique was that of principal component analysis (PCA).

Method 5. Principal component analysis was performed on the $24 \times 24$ character correlation matrix. Three factors were extracted. The character factor loading was used to calculate the OTU factor scores, or projections, in three-factor space.

To examine ordination efficiency, the Euclidean Distances between all pairs of OTU's in the factor space were calculated and the resulting matrix was compared with the original distance matrix (Method 1) using the cophenetic correlation coefficient $(r)$.

\section{Results}

\subsection{Phenogram between taxa}

In the phenogram of distance between the taxa (Fig. 26) a main group and an isolated OTU (OTU 14 ) is recognized.

The main group contains two main clusters, the first comprising OTU's 1, 2, 4, 25, 6, 5, 27, 24, $7,20,21,18,19,22$, and 23 , and the second with OTU's 3, 16, 15, 8, 12, 26,13, 17, 9, 10 and 11 .

Cluster 1 is divided into two groups: the first with OTU's 1, 2, 4, 25, 6, 5, 27 and 24, and the second with OTU's 7, 20, 21, 18, 19, 22 and 23.

In the phenogram of the correlations between the taxa (Fig. 27), two main clusters are recognized.

Cluster 1 contains two groups. The first comprises OTU's 1, 5, 27, 4, 25, 6, 24, 2, and the second OTU's 7, 20, 21, 18, 19, 22 and 23.

Cluster 2 contains one group and a very heterogeneous nucleus (OTU's 9 and 14), the group comprises OTU's $3,16,15,8,10,11,12,26,13$ and 17.

The relationships among the OTU's observed in the distance phenogram are similar to those in the correlation one, with the diference that in the latter, OTU 14 ( $R$. vittatus) is included in cluster 2 , and related to OTU 9 ( $R$. arcuiger) at a low level of similarity.

\subsection{The Prim Network}

Drawn in the bidimensional graph of the PCA, the network shows that there are four important points of junction, through which a great number of OTU's are connected. They are a) OTU 16 and 23, which relate OTU's from cluster 1 and cluster 2 and b) OTU 4 and 27, which interrelate OTU's from cluster 1 .

\subsection{Principal component analysis}

Three principal components were obtained. Component I accounts for $30.8 \%$ of the total variation; Component II for $14.6 \%$ and Component III for $10.1 \%$ (Total $55.4 \%$ ). 


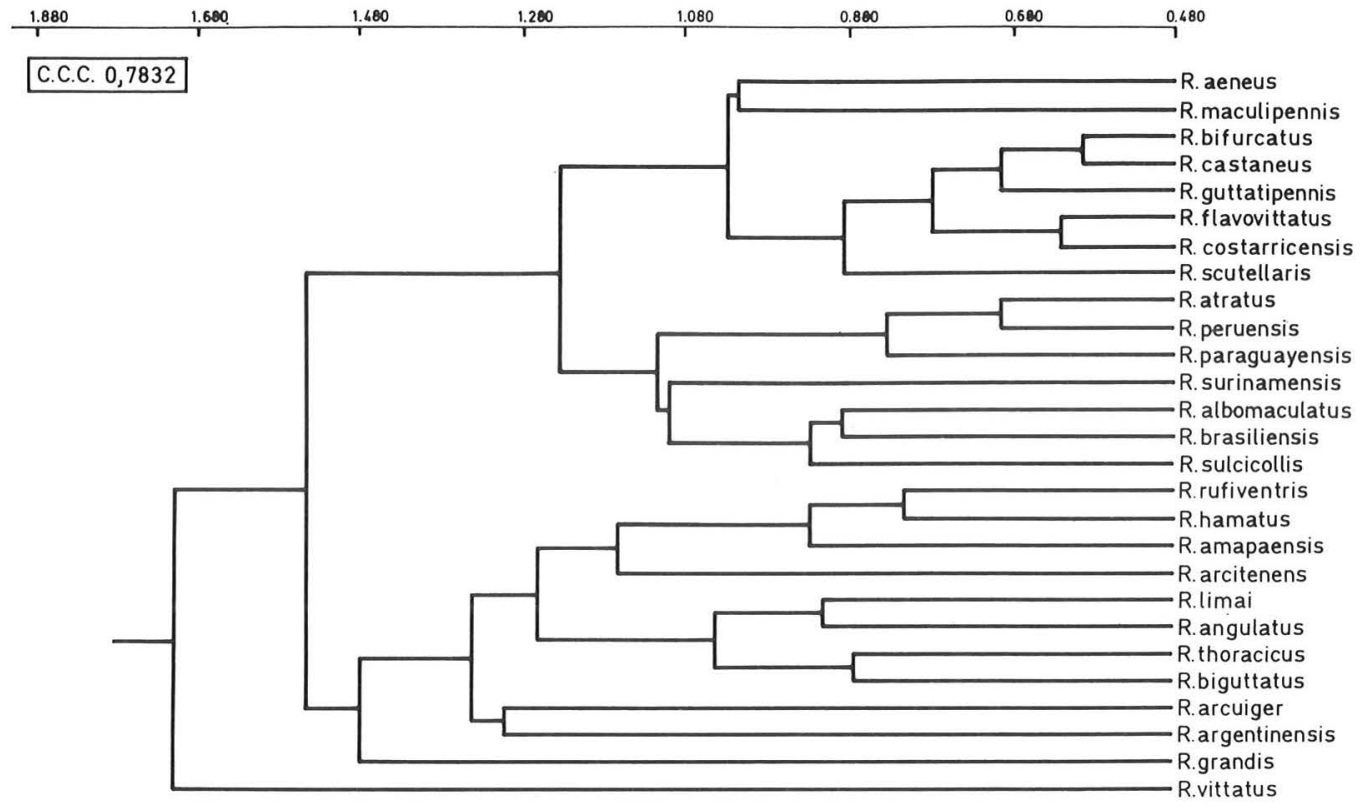

Fig. 26. UPGMA of taxonomic distance between the species of the genus Rasahus.

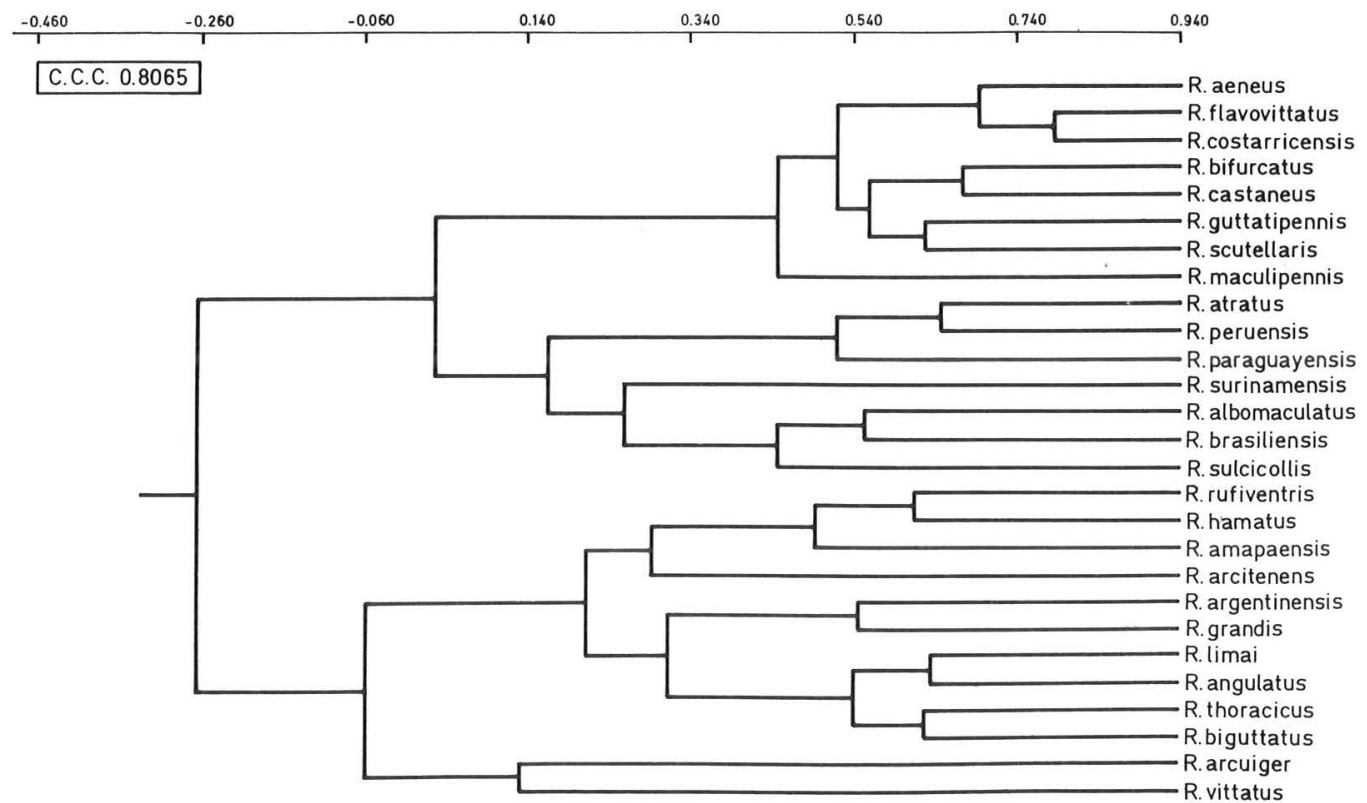

Fig. 27. UPGMA of correlations phenogram between the species of the genus Rasahus. 
In factor I, which is a good discriminator among the main clusters, the most important characters are: the shape of the pygophore (c. 9), pattern of the hemelytra (c. 15), shape of the parameres (c. 23) and shape of the postocular region (c. 11). Factor II is a good discriminator of the OTU's of cluster 1); the characters are: the width of the pronotum (c. 2), width of the abdomen (c. 3) and body length (c. 1). Factor II has the following characters: ratio rostral segment I / segment III (c. 8), ratio head length / pronotum length (c. 5) and basal plate complexity (c. 24).

The relations between the OTU's in the bidimensional space delimited by factors I and II (Fig. 28), I and III, and II and III are similar. Clusters 1 and 2 are separate, and OTU 14 has an isolated position between the taxa. Cluster 1 is also divided into two main groups.

\subsection{Phenogram of the characters}

At a similarity level of 0.86 , two clusters are formed. One of them constituted by the quantitative continuous characters: pronotum width (c. 2), abdomen width (c. 3) and length (c. 1). The other cluster is formed by qualitative characters of the male genitalia. These are the shape of the pygophore (c. 19), median distal region of the medial process of the pygophore (c. 21), inferior edge of the pygophore (c. 20) and shape of the parameres (c. 23); at a lower level of similarity, the shape of the postocular region (c. 11) is correlated to them.

The rest of the characters are related at a low level of similarity.

\section{Discussion}

\subsection{Delimitation of the groups and phenetic re- lationships}

The numerical analysis of the genus Rasahus confirmed that at present it comprises 27 species, divided into three groups.

The first group (OTU 1, 2, 4, 25, 6, 27, 24, 7, $20,21,18,19,22$, and 23) and the second group (OTU 3, 16,15, 8, 12, 26, 13, 17, 9, 10 and 11) are designated the scutellaris (Figs. 29-34) and hamatus groups (Figs. 37-43), respectively. The third group, containing OTU 14, is the vittatus group (Figs. 44-49).
OTU 14 has a contradictory position. In the phenogram of the distances between taxa (Fig. 26), it is isolated from the scutellaris and hamatus groups. On the other hand, in the phenogram of the correlations between taxa (Fig. 27), it is included in the hamatus group. In the Prim Network which is placed in the PCA Scatter Diagram (Fig. 28), it occupies an intermediate position between the scutellaris and hamatus groups. Accordingly OTU 14 is considered to be separated from other groups, but to be closely related to the scutellaris group. The characters shared are the shape of the postocular region (c. 11), pattern of the hemelytra (c. 15) and shape of the parameres (c. 23), as reflected in the first main axis of the PCA (Fig. 28).

The three groups are separated in the phenogram of the distances between taxa (Fig. 26). In the scutellaris group are two subgroups of species that have the same relationship in the two phenograms (Figs. 26, 27), which was also observed when Factor II was plotted (Fig. 28).

\subsection{Characters of diagnostic importance}

The characters of diagnostic importance are: the shape of the pygophore (c. 19), shape of the parameres (c. 23), shape of the postocular region (c. 11) and hemelytra pattern (c. 15). These characters differentiate the groups of species.

The width of the pronotum (c. 2), width of the abdomen (c. 3) and length (c. 1) are good discriminators between the two subgroups of species in the scutellaris group.

The two clusters of characters formed at the high levels of similarity in the phenogram of the correlations between characters coincide with most of the characters given by Factors I and II of the PCA.

\subsection{Genus Rasahus Amyot \& Serville}

Type species: Peirates sulcicollis Serville 1843

Geographical distribution: Neartic and Neotropical

In 1843 Amyot \& Serville proposed the name of the genus for a species that Serville named Peirates sulcicollis.

In 1866 Stål described Macrosandalus, Sphodrocoris and Callisphodrus, but in 1872 he treated them as synonyms. 


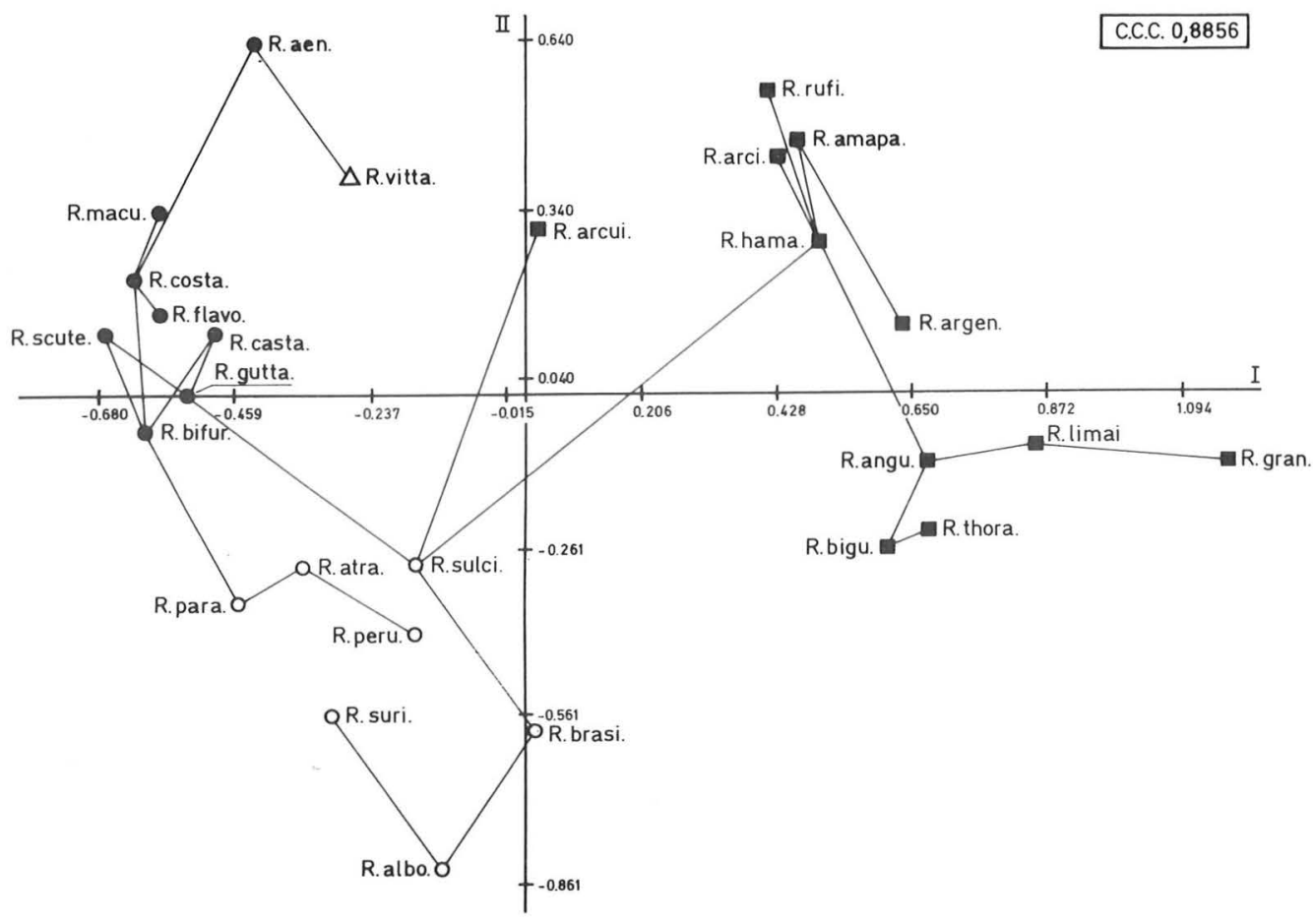

Fig. 28. Prim Network imposed on Factors I and II of Principal Component Analysis. Scutellaris group, subgroup $1=\boldsymbol{\bullet}$, subgroup $2=0$, hamatus group $=\mathbb{\square}$, vittatus group $=\Delta$.

Up to 20 different species were enumerated by Lethierry \& Severin (1896), but many names were synonyms or wrongly placed under Rasahus. Champion (1899) made a key for eight species from Central America. Wygodzinsky (1955) mentions 17 species. At present, 27 species are considered to belong to this genus (Coscarón, 1983, 1986, Coscarón \& Maldonado Capriles 1988).

The genus comprises three groups of species: scutellaris, hamatus and vittatus.

\section{Scutellaris group (Figs. 29-34)}

Postocular region rounded (Figs. 29, 34), hemelytra without a well-defined oval dot over $\mathrm{Cu}$ (Figs. 29, 34) (except R. sulcicollis), pygophore quadrangular (Fig. 30), inferior edge sinuose (Fig. 30) or with an evagination (Fig. 35), median distal region of the medial process of the pygophore curved (Figs. 30, 35, 36) (except in R. maculipen- nis), parameres subtriangular (Figs. 31, 32), basal plate simple (Fig. 33).

There are two subgroups of species: one consists of species that are small to medium (9.1 to $14.1 \mathrm{~mm})$ (Fig. 29):

$R$. aeneus (Walker), R. maculipennis (Lepelletier and Serville), R. bifurcatus Champion, $R$. castaneus Coscarón, $R$. guttatipennis (Stål), $R$. flavovittatus Stål, R. scutellaris (Fabricius).

The other subgroup contains bigger species (16 to $23.5 \mathrm{~mm}$ ) (Fig. 34):

$R$. atratus Coscarón, $R$. peruensis Coscarón, $R$. paraguayensis Coscarón, $R$. surinamensis Coscarón, $R$. albomaculatus Mayr, R. brasiliensis Coscarón, $R$. sulcicollis (Serville).

Geographical distribution: U.S.A., Guatemala, Belice, El Salvador, Costa Rica, Panamá, Venezuela, Colombia, Trinidad, Guyana, Surinam, Guayana, Brazil, Ecuador, Perú, Bolivia, Paraguay and Argentina. 


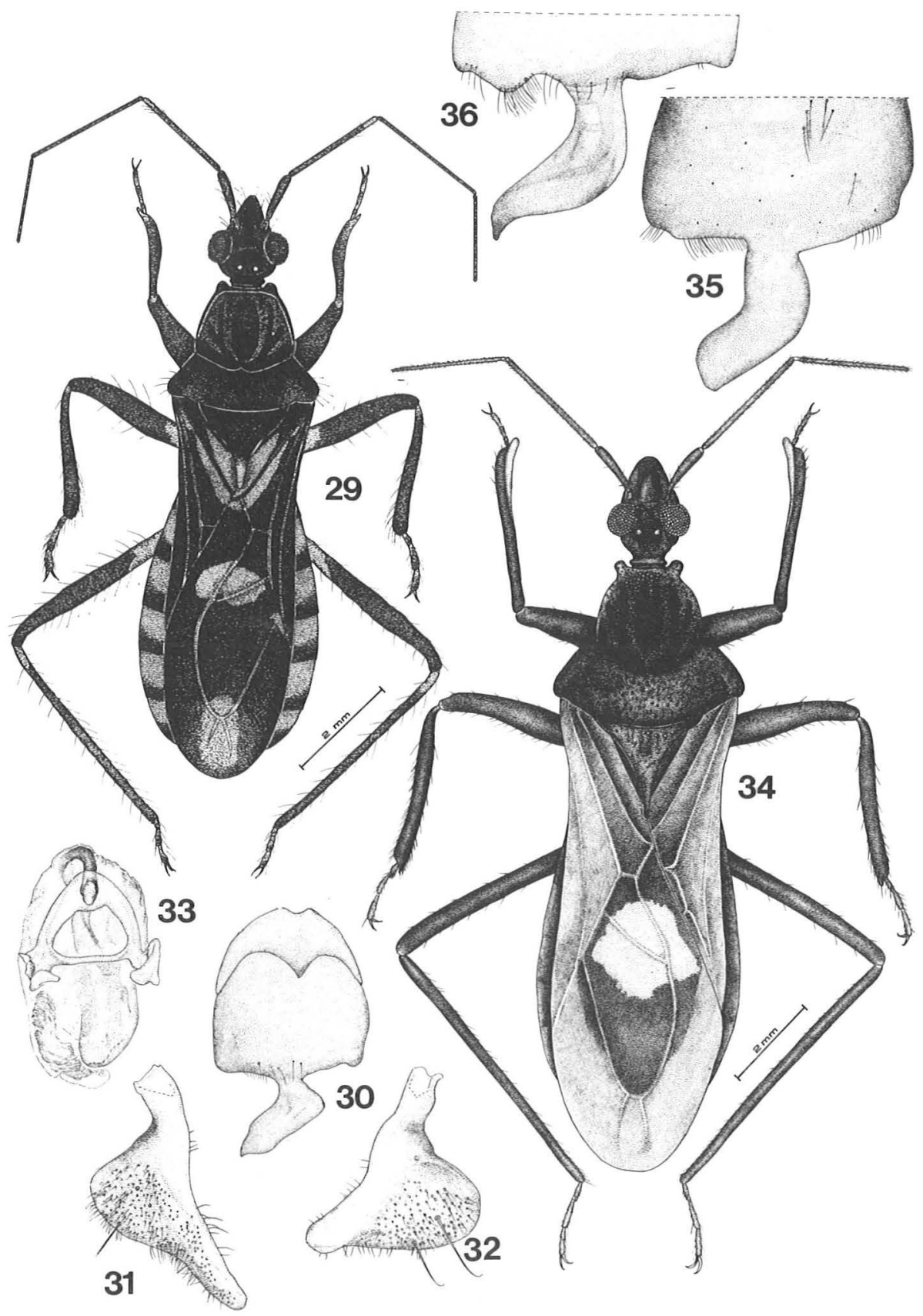

Figs. 29-36. Scutellaris group. R. scutellaris, 29, dorsal aspect; 30, male genitalia, ventral aspect; 31 and 32 , parameres; 33, basal plate. $R$. peruensis, 34, dorsal aspect; 35, medial process of pygophore. R. paraguayensis, 36 , medial process of pygophore. 


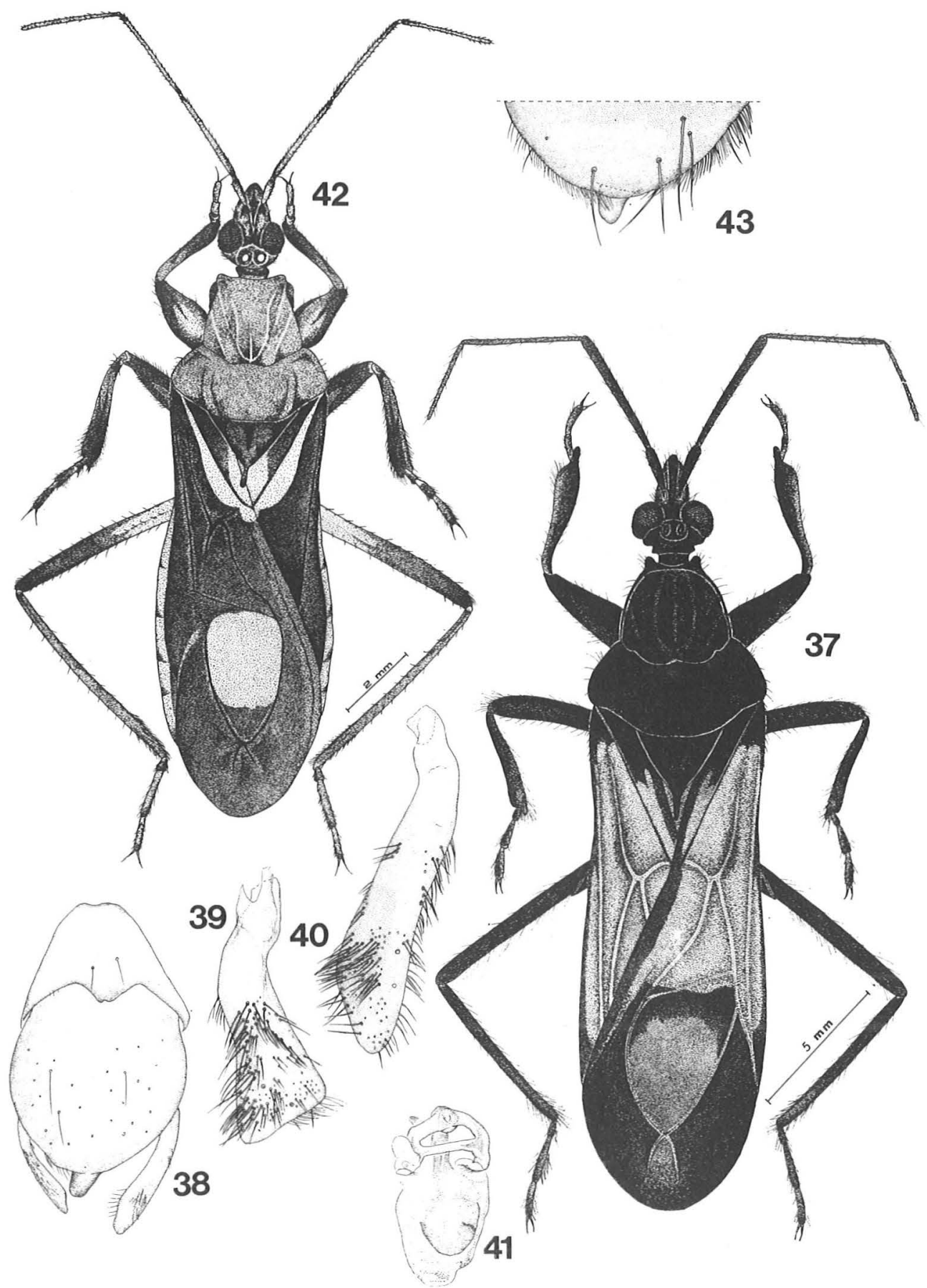

Figs. 37-43. Hamatus group. R. grandis, 37, dorsal aspect; 38, male genitalia, ventral aspect; 39 and 40, parameres; 41 , basal plate. $R$. hamatus, 42 , dorsal aspect; 43 , medial process of pygophore. 


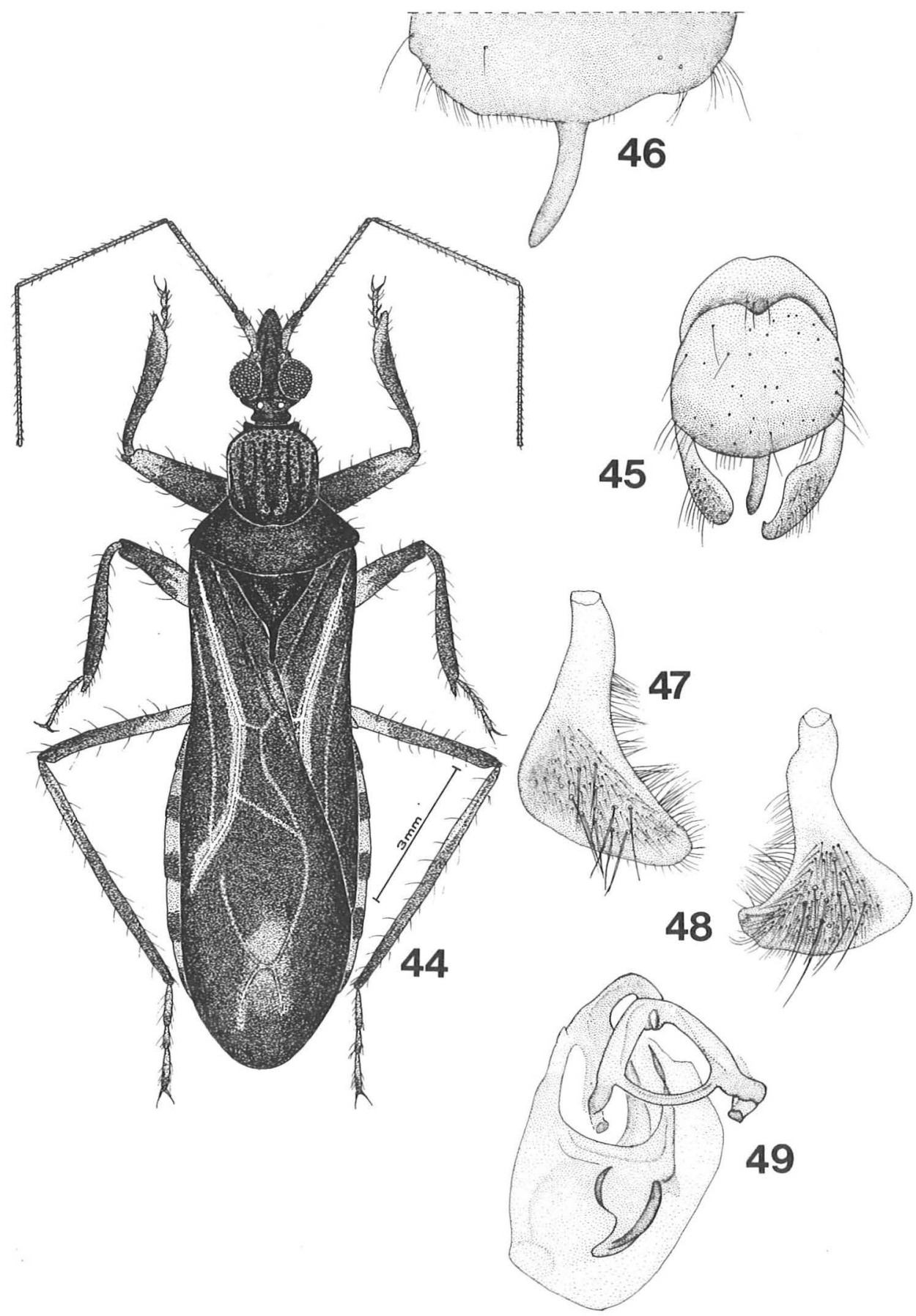

Figs. 44-49. Vittatus group. $R$. vittatus, 44 , dorsal aspect; 45 , male genitalia, ventral aspect; 46 , medial process of pygophore; 47 and 48 , parameres; 49 , basal plate. 


\section{Hamatus group (Figs. 37-43)}

Postocular region rounded (Fig. 42) or angular (Fig. 37), hemelytra with a well-defined dot over $\mathrm{Cu}$ (Figs. 37, 42), pygophore rounded (Fig. 38), inferior edge straight (not sinuose nor with evaginations) (Figs. 38, 43), median distal region of the medial process of the pygophore not curved (Figs. 38, 43), parameres subrectangular (Figs. 39, 40), basal plate simple (Fig. 41).

The species are: $R$. rufiventris (Walker), $R$. hamatus (Fabricius), $R$. amapaensis Coscarón, $R$. arcitenens Stål, $R$. limai Pinto, $R$. angulatus Coscarón, $R$. thoracicus Stål, R. biguttatus (Say), $R$. arcuiger (Stål), $R$. argentinensis Coscarón and $R$. grandis Fallou.

Geographical distribution: the same countries as in the scutellaris group (except Guyana); also Cuba, República Dominicana, Jamaica, Nicaragua and Uruguay.

\section{Vittatus group (Figs. 44 49)}

Postocular region rounded (Fig. 44), hemelytra without a well-defined dot over $\mathrm{Cu}$ (Fig. 44), subrectangular pygophore (Fig. 45), inferior edge straight, median distal region of the medial process of the pygophore not curved (Fig. 46), parameres subtriangular (Figs. 47, 48), basal plate complex (Fig. 49).

One species: $R$. vittatus Coscarón

Geographical distribution: Brazil (Bahía, Pernambuco, Espíritu Santo).

Observations: Nearest to the scutellaris group.

Acknowledgements. This paper was written while I was holding an External Fellowship from the National Council of Research of Argentina (CONICET). First of all, I want to thank Dr. A. Lanteri, who generously provided computational assistance, Dr. M. Cigliano and Lic. J. Morrone for their constructive suggestions, especially for the improvement of the numerical techniques and Drs. M. Loiácono and N. Díaz for their assistance and valuable suggestions. Furthermore, I want to express my gratitude to Drs. P.H. van Doesburg, G. Povel, A. Albrecht and A. Jansson for all their helpful criticism of the manuscript. This investigation was partly supported by a grant from the Finnish Academy of Sciences.

\section{References}

Amyot, C. J. B. \& Audinet-Serville 1843: Histoire naturelle des insectes. Hémiptéres. - Paris. 675 pp.

Champion, G. C. 1897-1901: Insecta-Rhynchota, Hemiptera-Heteroptera. - Biologia Centrali Americana 16. London. 416 pp.

Coscarón, M. C. 1983: Revisión del género Rasahus (Insecta, Heteroptera, Reduviidae). - Rev. Mus. La Plata, 13, Secc. Zool. 136:75-138.

- 1986: Nueva especie del género Rasahus Amyot y Serville 1843 del Brasil (Heteroptera, Reduviidae, Peiratinae). - Rev. Bras. Entomol. 30(2):303-305.

Coscarón, M. C. \& Maldonado Capriles, J. 1988: Contribution to the knowledge of the genus Rasahus Amyot and Servile 1843 (Hemiptera: Reduviidae): description of a new species. - J. Agric. P.R. 72(2):247-250.

Crisci, J. V. \& López-Armengol, M. F. 1983: Introducción a la teoría y práctica de la taxonomía numérica. - Sec. Gral. OEA. Monografía N²6. Serie Biología. Washington, D.C. $128 \mathrm{pp}$.

Davis, N. T. 1966: Contribution to the morphology and phylogeny of the Reduvioidea (Hemiptera: Heteroptera). Part III. The male and female genitalia. - Ann. Entomol. Soc. Amer. 59:911-924.

- 1969: Contribution to the morphology and phylogeny of the Reduvioidea (Hemiptera: Heroptera). Part IV. The Harpactoroid complex. - Ann. Entomol. Soc. Amer. 62(1):74-94.

Dupuis, C. 1955: Les génitalia des Hemiptères. - Mem. Mus. Nat. d'Hist. Nat. N¹, 6(4):183-278.

- 1963: Progrès récents de l'étude des génitalia des Heteroptera (étude bibliographique). - Thesis, Fac. Sci. Univ. Mus. Nat. d'Hist. Nat. 100 pp.

Lent, H. \& Jurberg, J. 1966: Revisâo dos Piratinae Americanos. II. O gênero "Phorastes" Kirkaldy, 1900, com um estudo sôbre a genitalia das especies (Hemiptera, Reduviidae). - Rev. Brasil. Biol. 26(3): 297-314.

Lent, H. \& Wygodzinsky, P. 1979: Revision of the Triatominae (Hemiptera, Reduviidae), and their significance as vectors of Chagas disease. - Bull. Amer Mus. Nat. Hist. 163(3). 520 pp.

Lethierry, L. \& Severin, G. 1896: Catalogue général des Hemiptères. - Bruxelles \& Berlin. 275 pp.

Sneath, P. H. \& Sokal, R. R. 1973: Numerical taxonomy: the principles and practice of numerical classification. San Francisco, Freeman \& Co. 573 pp.

Stål, C. 1866: Bidrag till reduviidernas kännedom. Öfversigt Kongl. Vetenskaps-Akad. Förhandlingar 1866(9):235-302.

- 1872: Genera Reduviidarum Europae disposuit. Öfversigt Kongl. Vetenskaps-Akad. Förhandlingar 1872(6):43-48.

Wygodzinsky, P. 1949: Elenco sistemático de los Reduviiformes Americanos. — Monogr. Inst. Med. Reg. 1: 103 pp.

Received 12.IX.1989 